\title{
The importance of grazing regime in the provision of breeding habitat for grassland birds: The case of the endangered little bustard (Tetrax tetrax)
}

\author{
Nuno Faria ${ }^{a, b, c, *}$, João E. Rabaça ${ }^{a, b}$, Manuel B. Morales ${ }^{c}$ \\ ${ }^{a}$ LabOr - Laboratory of Ornithology, Department of Biology, University of Évora, 7002-554 Évora, Portugal ${ }^{1}$ \\ ${ }^{\mathrm{b}}$ Research Group on Mediterranean and Landscapes Ecosystems-ICAAM, University of Évora, 7002-554 Évora, Portugal ${ }^{2}$ \\ c Departamento de Ecología, Universidad Autónoma de Madrid, 28049 Madrid, Spain
}

\section{A R T I C L E I N F O}

\section{Article history:}

Received 25 October 2011

Received in revised form 19 February 2012

Accepted 20 March 2012

\section{Keywords:}

Tetrax tetrax

Stocking rates

Livestock

Pasture management

Vegetation structure

Green plants

\begin{abstract}
A B S T R A C T
In Mediterranean dry grasslands, grazing by domestic animals is an important agricultural activity on dry grasslands. Several bird species occur in these grazed habitats and are now experiencing a near continuous decline. We investigated the impact of livestock grazing on the threatened little bustard (Tetrax tetrax L.). The study was conducted at the NATURA 2000 Site/Important Bird Area of Cabrela, Portugal. Our main goals were to investigate responses of little bustard territorial males and breeding females to different livestock management practices, namely pasture types, stocking rates and sward structure. Bird distribution was surveyed using car and foot surveys. Data on grazing was supplied by land managers every 10 days from February to June through field interviews. Generalised additive models and model averaging were used to compute predictive models. Results indicate that higher probabilities of occurrence were found in long-term pastures and under light-moderate grazing conditions (stocking rates around $0.4 \mathrm{LU} / \mathrm{ha}$ ). Conversely, lower probabilities of occurrence were found in ungrazed or heavy grazed fields. Males occurred mostly in large fields, but this variable seemed to be less important for females. On the other hand, green plant cover and the vegetation height were good predictors for the occurrence of females but not for males. Females used mostly pastures with vegetation height around $20-25 \mathrm{~cm}$. Our results suggest that grazing management plans that aim to conserve little bustard populations should consider (1) the maintenance of the larger long-term pastures and (2) the use of light-moderate stocking rates $(0.2-0.6 \mathrm{LU} / \mathrm{ha})$.
\end{abstract}

(c) 2012 Elsevier GmbH. All rights reserved.

\section{Introduction}

In Europe 173 bird species with an unfavourable conservation status occur in grassland habitats (Tucker \& Dixon 1997). Most of these taxa are resident species associated with Mediterranean pseudosteppes (Suárez et al. 1997) and sparse pastoral of Quercus suber (L.) and/or Q. rotundifolia (Lam.) forested areas, hereafter referred broadly as dry grasslands. Several of these species are experiencing a nearly continuous decline and are now classified as threatened or near-threatened (e.g. the great bustard Otis tarda L., the lesser kestrel Falco naumanni Fleischer and the little bustard Tetrax tetrax L.) at different geographic levels (BirdLife International 2008; Cabral et al. 2006; Madroño et al. 2004; Rocamora \& Berthelot 1999).

\footnotetext{
* Corresponding author. Current address: Departamento de Ecología, Universidad Autónoma de Madrid, 28049 Madrid, Spain.

E-mail address: farnuno@gmail.com (N. Faria).

1 Tel. +351266 760897; fax. +351266 760914.

2 Tel. +351266 760885; fax. +351266 760913.
}

Originating mostly from human depletion of pristine Mediterranean forests (Blondel \& Aronson 1999; Suárez et al. 1997; Tucker \& Dixon 1997), these anthropogenic habitats have been managed historically for extensive livestock grazing and cereal crop farming in a traditional low-intensity rotating system (Donázar et al. 1997; Gómez-Limón \& Fernández 1999). However, in the last decades an increase in livestock numbers has occurred, partly induced by the European Common Agricultural Policy (CAP) of the European Union (EU), through financial incentives to farmers (Donázar et al. 1997; Suárez et al. 1997). On the other hand, scientific advances on dairy science and rangeland management allowed for the increase of livestock densities in pastures and the use of new grazing areas formerly considered poor or unsuitable for livestock.

Increased livestock and crop yields led to an intensification of agricultural landscapes and a loss of biodiversity (Aich \& Waterhouse 1999; Donald et al. 2002; Geiger et al. 2010; Potts 1997). Presently, overgrazing represents the fourth most important threat to grassland habitats and their associated bird species, after crop intensification, pesticide use and land abandonment (Tucker \& Dixon 1997). Cattle numbers increased 36\% between 